\title{
Analysis of Climate Change Education (CCE) Programs: Focusing on Cultivating Citizen Activists to Respond to Climate Change
}

\author{
Na-Eun Park \\ Department of Science Education, Seoul National University, \\ Seoul, Republic of Korea \\ goorenani@snu.ac.kr \\ Seung-Urn Choe \\ Department of Earth Science Education, Seoul National University, \\ Seoul, Republic of Korea \\ suchoe@snu.ac.kr \\ Chan-Jong Kim \\ Corresponding author, \\ Department of Earth Science Education, Seoul National University, \\ Seoul, Republic of Korea \\ chajokim@snu.ac.kr
}

Received: 14 February 2020 | Revised: 30 April 2020, 25 May 2020 | Accepted: 1 June 2020

\begin{abstract}
Climate change education (CCE) programs should foster citizen response to climate change by integrating knowledge/skill development with reflection on the need for actively changing current social systems and personal actions. An analytical framework was developed to examine 16 Korean and international CCE programs to identify (1) structure and content and (2) to categorize action-emphasized climate change education (AECCE) programs. Results show most CCE programs are for elementary levels and place emphasis on knowledge/skill development, but not on action. AECCE categorized programs were less structured, included more reflexive activities, and promoted more action. Korean AECCE programs offered online content and promoted action at the personal level. International AECCE programs balanced online/real-life content and promoted more action at the socio-political level. AECCE programs need


to foster values/attitudes and to promote participation and action at all grade levels, should balance potential and practical components, and target both personal and socio-political levels of action.

\section{초록}

기후변화교육(CCE) 프로그램은 지식, 기능의 함양과 현재 사회 및 개인 행동의 변 화 필요성에 대한 성찰을 통합함으로써 기후변화에 대한 시민의 대응을 촉진해야 한다. 이 연구에서는 기후변화교육 프로그램의 (1) 구조와 내용을 검토하고, (2) 실천 이 강조된 기후변화교육(AECCE) 프로그램을 분류하기 위한 분석틀을 개발하고, 이 를 바탕으로 한국과 외국의 CCE 프로그램 16 개를 분석하였다. 분석 결과, 대부분의 $\mathrm{CCE}$ 프로그램은 초등학교급에 해당하였으며 실천보다는 지식과 기능의 영역이 더 욱 강조되었다. AECCE로 분류된 프로그램들은 보통의 $\mathrm{CCE}$ 프로그램보다 구조화 정도가 상대적으로 낮았으며 성찰적 활동과 실천을 더욱 많이 포함하였다. 한국 AECCE 프로그램은 온라인 맥락과 개인적 수준에서의 대응 행동을 주로 포함하였 다. 외국 AECCE 프로그램은 온라인과 실제적 맥락을 균형적으로 포함하였으며, 사 회정치적 수준에서의 대응 행동을 더욱 강조하였다. AECCE 프로그램은 모든 학년 에서 가치와 태도를 함양하고 참여와 실천을 장려하여 잠재적 요소와 실천적 요소 를 균형 있게 포함하여야 하며, 개인적 수준과 사회정치적 수준의 행동을 모두 이 끌어낼 수 있어야 한다.

\section{Keywords}

citizen activists - climate change education - program analysis

\section{Introduction}

Climate change is one of the major socio-scientific issues and one of the greatest potential risks facing modern society. According to the Intergovernmental Panel on Climate Change (IPCC) Fifth Assessment Report (Pachauri \& Meyer, 2014), it is obvious that the average temperature of the earth's climate system is rising. Most of the observed changes, such as melting glaciers and rising sea levels, have not occurred for decades to thousands of years. The main causes of recent climate change are human activities, and unless humans actively respond to climate change, the risks will become increasingly pervasive and have irreversible effects on humans and ecosystems (Pachauri \& Meyer, 2014).

Therefore, efforts to find common social solutions through social discourse on how to deal with the risks of climate change are very important and urgent. 
In particular, future generations will be more affected by climate change, so children and adolescents need to play an important role in proactively responding to climate change as stakeholders on the issues (Yun, 2009). Climate change education (CCE) has emerged as a fundamental solution to cultivate awareness about responding to climate change. In response to the need and urgency for CCE, various discussions have been made on the direction of CCE. The first major trend was that CCE should be interdisciplinary and multidisciplinary (Yun, 2009), because climate change is an issue closely related to social structures. The second was on action-oriented CCE, with a focus on enabling students to act responsibly on climate change issues (Cordero et al., 2008; Lester et al., 2006). This study reflected both trends, particularly emphasizing actions to respond to climate change in different contexts and levels.

CCE has been studied and implemented as an important issue in many countries around the world, such as the United States, the United Kingdom, and Germany. For example, in the United Kingdom, environmental education policies have recently integrated global education agendas such as sustainable development goals (SDG s) and global citizenship education. The United Kingdom also proposed the use of an integrated approach of curriculum, campus, and community $\left.{ }_{3} \mathrm{C}\right)$ to help students actively seek solutions at the global and regional levels for environmental issues such as climate change (Kim et al., 2013). Research on CCE in Korea is still in its infancy; therefore, constructive discussions for more effective CCE are strongly required (Park et al., 2013). These discussions need to be conducted on a cyclical process consisting of analyzing, developing, and applying CCE programs. However, few studies have been conducted on the analysis of CCE programs. An analysis of research on CCE in elementary schools in Korea (Park et al., 2013) showed that very few studies have theoretically or empirically analyzed the current status of CCE.

In this study, we focused on the direction of action-oriented CCE and analyzed existing Korean and international CCE programs on the following three topics: (1) structure and content of the CCE programs, (2) characteristics of action-emphasized CCE (AECCE) programs, and (3) comparison of the characteristics of Korean and international AECCE programs. The results of this study, an integrated review of CCE programs, could provide a basis and implications for developing future CCE programs.

\section{$2 \quad$ Background and Related Literature}

\subsection{How to Respond to Climate Change}

In response to climate change, the international community adopted the United Nations Framework Convention on Climate Change (UN FCCC) in 1992, 
promising to reduce greenhouse gases under the principle of common but differentiated responsibilities. In 1997, the Kyoto Protocol mandated the reduction of quantitative greenhouse gases in developed countries. In 2015, the adoption of the Paris Agreement created a universal framework for all countries to reflect on their own situations and to participate in comprehensive climate action (MFA, 2015). Responses to climate change can be divided into mitigation and adaptation strategies. Mitigation focuses on reducing greenhouse gas emissions, which are the major causes of climate change, while adaptation focuses on reducing human and natural vulnerabilities to the effects of climate change (Anderson, 2012).

Public participation in responding to climate change is also important. Beck (1986) emphasized reflexive modernization as an alternative to risk society and argued that modern society needs critical and reflexive people who actively participate in social problems. Thus, for climate change, people should be able to respond not only at the individual level, but also at the social level. It is time for education to play an important role in fostering reflexive citizens to actively intervene and cope with common risks in risk society (Jeong, 2014).

\section{2}

The Direction of CcE

2.2.1

Implications for CCE from Discussions in Environmental Education

The goal of environmental education is to cultivate citizens who act to protect and improve the environment (Kim \& Shin, 2012; Hungerford \& Volk, 1990). In this regard, the purpose of environmental education can be divided into four areas: the acquisition of information and knowledge, the acquisition of skills, the cultivation of values and attitudes, and the expansion of action and participation (Seo et al., 1999). The concept of ecological citizenship has also attracted attention. Ecological citizenship refers to the ability to ecologically reconstruct human-nature relationships with a conscious focus on identifying and understanding social structures that result in environmental problems (Kim, 2011). This type of citizenship is characterized as being non-territoriality and emphasizes the need to understand incompatible responsibilities based on relationships between different groups (Dobson, 2003). It also requires personal and social action, taking into account environmental issues arising in the public and private areas (Kim, 2013; Dobson, 2003).

Kim and Choi (2010) compared and analyzed the discussions that presented the main principles and directions of what to consider when dealing with climate change in environmental education through a literature review, proposing guidelines for CCE in environmental education (Table 1). They emphasized an integrated understanding of climate change, exploring the meaning of action on 
TABLE 1 Guidelines for CCE presented in Kim and Choi (2010)

Guidelines

Comprehensive understanding of climate change

Exploring the meaning of response to climate change

Reflection on social systems and ways of life

Positive participation in the change process

\section{Contents}

Understanding the causes and impacts of climate change in the earth's system Understanding the link between how personal and social actions have positive or negative impacts on climate change Developing reflexive attitudes toward current social and economic systems and ways of life Providing the opportunity to find ways to participate at each level

climate change, reflection on current social systems and ways of life, and participation in positive change processes.

\subsubsection{Implications for CCE from Discussions in Science Education}

Science education is important in CCE because the processes, causes, and impacts of climate change are based on scientific concepts and principles. Sharma (2012) stressed that science education must be transformed so that students can play an active role as citizens in order to create societies that respond to climate change in an evidence-based and sustainable way. This is also related to the conceptual expansion of scientific literacy that represents the goal of science education. Roberts (2007) described scientific literacy in Vision I and Vision II, and then Aikenhead (2007) proposed the scientific literacy of Vision III. Vision I emphasizes scientific knowledge, and Vision II emphasizes the relationship between science, technology, society, and the environment. Vision II f further requires scientific engagement on social, cultural, political, and environmental issues (Liu, 2013; Aikenhead, 2007). The three are interdependent and can reinforce each other, and a scientifically literate person is expected to have all three types of scientific literacy (Liu, 2013).

There is a growing voice that science education should be directed towards participation and action. Hodson (2003) argued that traditional science education is not sufficient to solve modern complex social problems, and Bencze et al. (2012) emphasized activism in socio-scientific issues (SSI) education. They have stressed in common that modern society needs citizens to act with scientific and political literacy, and that science education should be directed towards socio-political action. 


\section{Approaches and Frameworks for Analysis of CCE Programs in} Prior Studies

Several studies have analyzed CCE programs based on various frameworks or perspectives for analysis. For example, for school-level CCE programs, Yun (2009) compared Korea's CCE programs to international CCE programs, such as those in California's Green Schools and Canada's Sierra Schools in Action. This was significant in that it suggested implications for the reorganization of the curriculum for CCE in Korea and the development of practical CCE programs through collective participation in schools. The study compared the implementation of CCE programs by describing the topics covered by each program. However, since we intended to analyze the current status of CCE programs through an integrated analysis framework, there was a difference in perspective on the analysis method from the study.

Kim and Shin (2013) compared Save Energy, Save Earth (SESE) program in Korea and National Energy Education Development Project (NEED) in the United States, which were examples of CCE programs. They analyzed the structure and content of the programs by analyzing the textbooks of each program. The structures of the programs were analyzed by comparing the types and connections of learning topics in the tables of contents, and the content was compared by describing the most prominent differences in the two programs, such as the types of activities and learning materials. The study was similar to this study in that it analyzed the CCE programs based on teaching materials and analyzed the structure and content of the programs in a dualistic way. However, Kim and Shin (2013) did not also provide a framework for an integrated analysis of CCE programs.

Hung (2014) analyzed CCE in the Singapore curriculum, focusing on students' learning outcomes and presented a conceptual framework for learning outcomes of CCE (Figure 1). The study stressed that CCE should address areas of knowledge, skills, values, and action that help students understand and act on the causes, impact, and management of climate change. This approach was consistent with the direction of CCE emphasized in our study. Hung (2014)

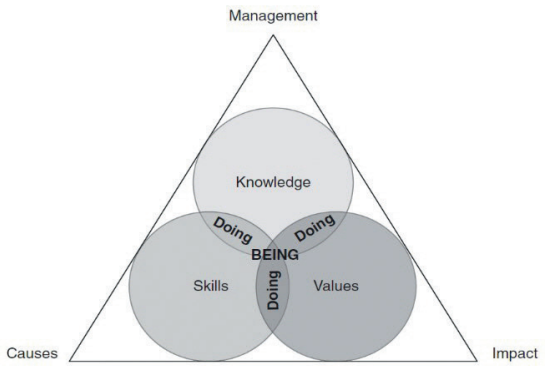

FIGURE 1

Conceptual framework for learning outcomes of CCE (Hung, 2014, p. 33) 
also presented several sub-areas: reminding and understanding for knowledge and analyzing and evaluating for skills. However, no specific sub-areas were presented for values or action.

In this study, we developed an analysis framework for an integrated review of CCE programs based on the direction of action-oriented CCE. We aimed to analyze the structure and content of existing CCE programs, the characteristics of AECCE programs, and the differences between Korean and international AECCE programs.

\section{$4 \quad$ Methodology}

\subsection{How to Develop Analysis Frameworks for cce Programs}

Based on the direction of action-oriented CCE, this study focused on cultivating action competency. Action competency refers to the ability to act responsibly and actively address social problems of the present and future (Jensen \& Schnack, 1997; Mogensen \& Schnack, 2010). Jensen and Schnack (1997) described knowledge, insight, commitment, visions, and action experiences as aspects of action competency. In addition, Carlsson and Simovska (2012) included skills in the knowledge area. We developed new analytical frameworks for CCE programs, considering the aspects of action competency and the framework of learning outcomes of CCE proposed by Hung (2014).

The conceptual background for developing the frameworks is shown in Figure 2. First, the knowledge, insight, and skills areas of action competency were simplified into areas of knowledge and skills that can be clearly distinguished, as suggested by Hung (2014). Visions could be included in a broader

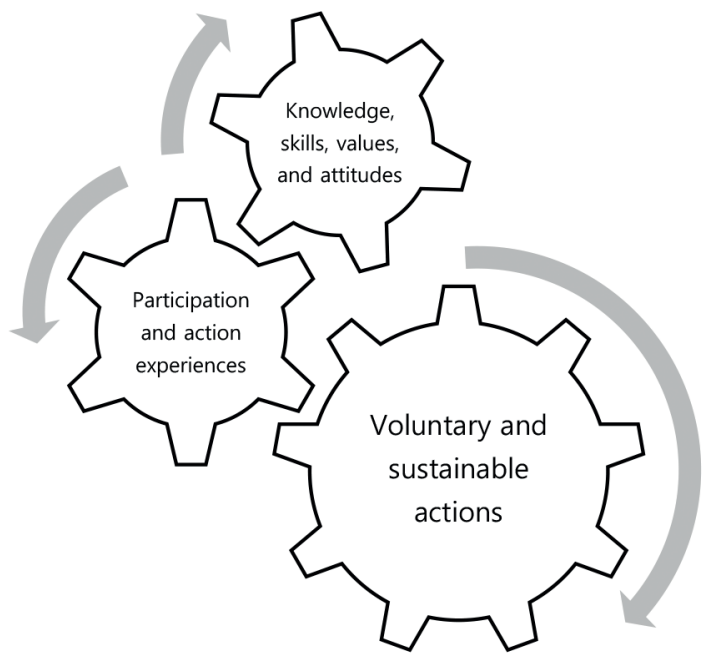

FIGURE 2

Conceptual background for developing analysis frameworks for CCE Programs 
sense of values, as suggested by Hung (2014). We also extended commitment to the broader sense of attitudes. Thus, the areas of knowledge, skills, values, and attitudes were considered potential aspects of CCE programs. Second, action experiences were emphasized in common in the aspects of action competency and the framework of Hung (2014). In addition, participation in preparing for action should be considered important. Therefore, we considered the areas of participation and action experiences as practical aspects of CCE programs. We expected that CCE programs could foster education of citizen activists who can act voluntarily and sustainably in response to climate change through interactions between these potential and practical aspects.

Based on this background, we developed analysis frameworks to analyze the structure and content of CCE programs. The structure analysis framework for CCE programs consists of five areas: object, form and size, degree of specification, range of content, and activity elements (Table 2). Each area is divided into sub-areas. The content analysis framework includes two major aspects: potential and practical. Potential aspects consist of three major areas: knowledge, skills, and values and attitudes (Table 3). Each area has three or four

TABLE 2 Structure analysis framework for CCE programs

Areas

Object

Form \& size

Range of content

Activity elements
Sub-areas

Grades

Independent

Modular

Number of learning topics

Low/High

Phenomena and principles

Causes

Impacts

Response

Planning and design

Survey

Data analysis

Experiments and analyzing results

Argumentation and decision-making

Predicting future scenarios

Creating products

Role play

Field trip 
TABLE 3 Content analysis framework for CCE programs

Aspects Areas Sub-areas Description

Potential Knowledge Scientific knowledge Scientific knowledge about climate aspects

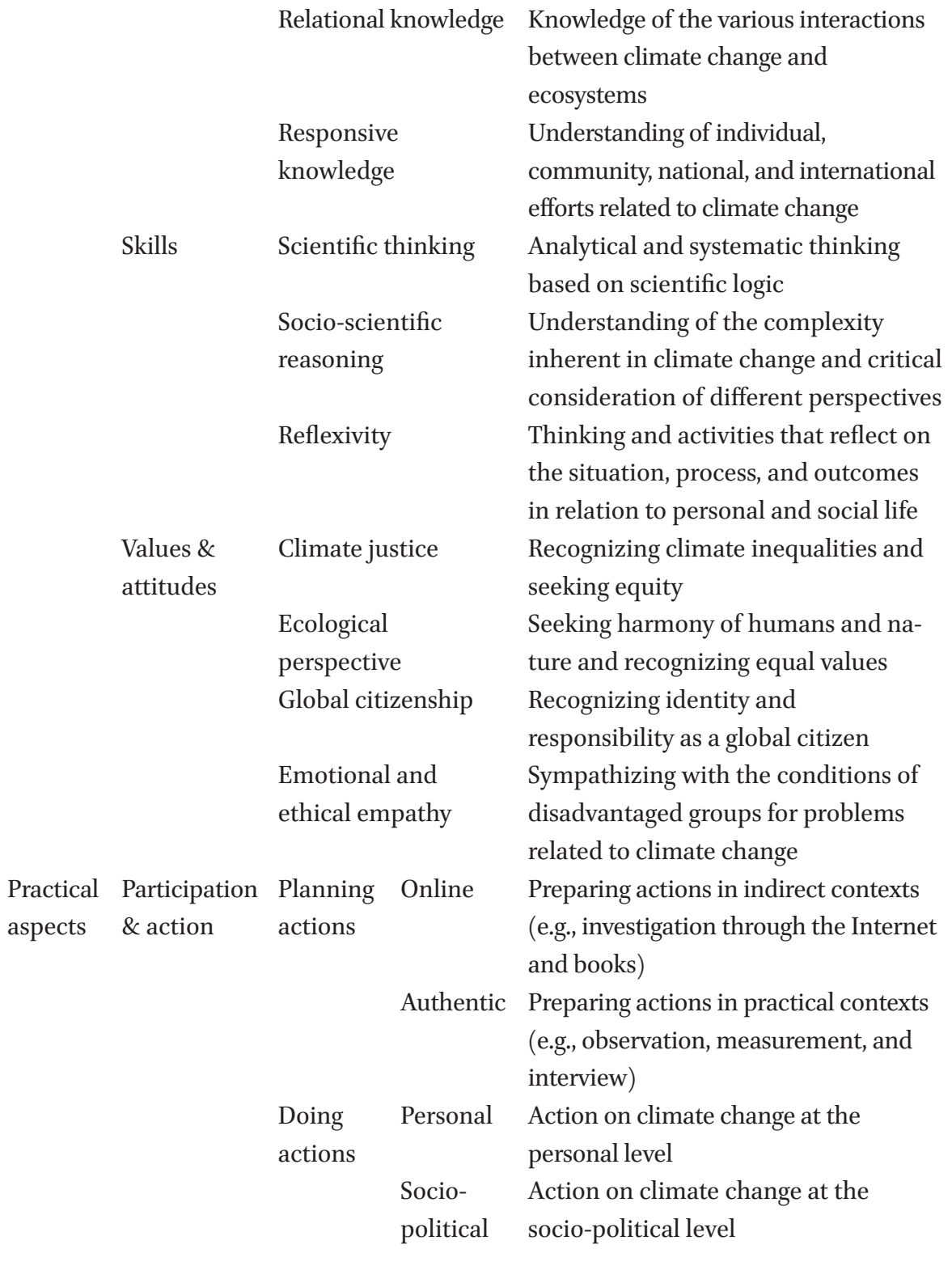


sub-areas. Practical aspects have one area, participation and action, and it is sub-divided into two sub-areas: planning actions and doing actions.

\subsection{How cce Programs for Analysis Were Collected and Selected}

The Korean and international CCE programs analyzed in this study were limited to those developed for elementary, middle, and high school students. Using search engines and Korean and international academic databases such as RIss (www.riss.kr) and PDU (search.proquest.com/pqdtglobal), the programs were searched using the keywords "CCE," “CCE program," and "CCE material." Among the $48 \mathrm{CCE}$ programs collected, we selected programs to be analyzed according to the following criteria. First, we targeted programs that provide teaching materials that can confirm the details and methods of implementation of the program. Such concrete teaching materials served as practical data for analyzing the structure and content of the programs. Second, we focused on analyzing CCE programs with comprehensive characteristics that reflect three or more of the areas of knowledge, skills, values and attitudes, and participation and action. For this reason, many of the programs were excluded from analysis. Finally, we selected 16 CCE programs for analysis, of which 10 were Korean and 6 were international. The list of programs is shown in Table 4.

\subsection{How to Analyze the cce Programs}

Based on the frameworks we developed, we analyzed the structure and content of each CCE program. Various materials related to programs such as textbooks,

TABLE 4 List of Korean and international CCE programs to be analyzed

\section{Korean programs International programs}
A. $\operatorname{Kim}(2015)$
K1. Oxfam Education (2015a)
B. $\operatorname{Kim}(2019)$
K2. Oxfam Education (2015b)
C. $\operatorname{Kim}(2017)$
L1. Stanford School of Earth, Energy, and Environmental
D. Kim (2013) Sciences (2011a)
E. Park (2012)
F. Oh (2010)
L2. Stanford School of Earth, Energy, and Environmental Sciences $(2011 \mathrm{~b})$
G. Woo (2011)
M. Trott (2017)
H. Jeong (2010)
N. University of Jyväskylä, University of Helsinki (2015)
I. Ju (2017)
J. Choi et al. (2013)

Note. Programs from the same authors were represented by the same letter, but with a different number following the school level. 
teaching and learning guides, and student activity sheets were reviewed in detail and analyzed descriptively. When analyzing the activity elements that were one of the areas in the structure analysis framework, we set a learning topic as an analysis unit and analyzed whether each activity element was included. For each learning topic specified in a program, a " 1 " indicated that an activity element was included and a "o" indicated that one was not. This method of analysis was applied equally to the content analysis of a program. According to the developed content analysis framework, the reflection of each sub-area of knowledge, skills, values and attitudes, and participation and action was analyzed for each learning topic of a program. Then, based on the results of each program's content analysis, the programs were categorized as either AECCE programs with emphasis on participation and action or typical CCE programs that did not, and we compared the structure and content characteristics between them. Finally, we reclassified the AECCE programs into Korean and international programs and compared the differences in structure and content between them.

The analysis process was made more objective by analyzing the programs together with a fellow researcher in the master's course in science education. As each analyzed the programs, discussions were continuously made on areas where opinions differed greatly. In addition, there were consultations with a group of eight or more fellow researchers consisting of master and doctoral students and professors in science education. In order to reduce errors in judgment, the analysis of each program was performed three or more times with a time interval of several days to obtain the final analysis results.

\section{5}

Results

The results of analysis of structure and content of the CCE programs investigated are presented first, followed by the characteristics of the AECCE programs, and finally a comparison of the AECCE programs in Korea and other countries is given.

\subsection{Structure Analysis}

Most CCE programs were for elementary school students (61.1\%), with few CCE programs (11.1\%) for high school students. Table 5 shows the number and ratio of programs by school level.

For the forms of the programs, 14 programs $(87.5 \%)$ were developed in independent form, and two programs were identified as modular. The size of the programs was, on average, 8.2 learning topics in one program, with a minimum of 5 and a maximum of 12. Additionally, there was no significant difference in overall proportion of programs with high $(56.3 \%)$ and low (43.8\%) degrees of 
TABLE 5 CCE programs by school level

\begin{tabular}{ll}
\hline School level & N (\%) \\
\hline Elementary school & $11(61.1 \%)$ \\
Middle school & $5(27.8 \%)$ \\
High school & $2(11.1 \%)$ \\
\hline
\end{tabular}

Note. Programs across multiple school levels were analyzed separately for each school level.

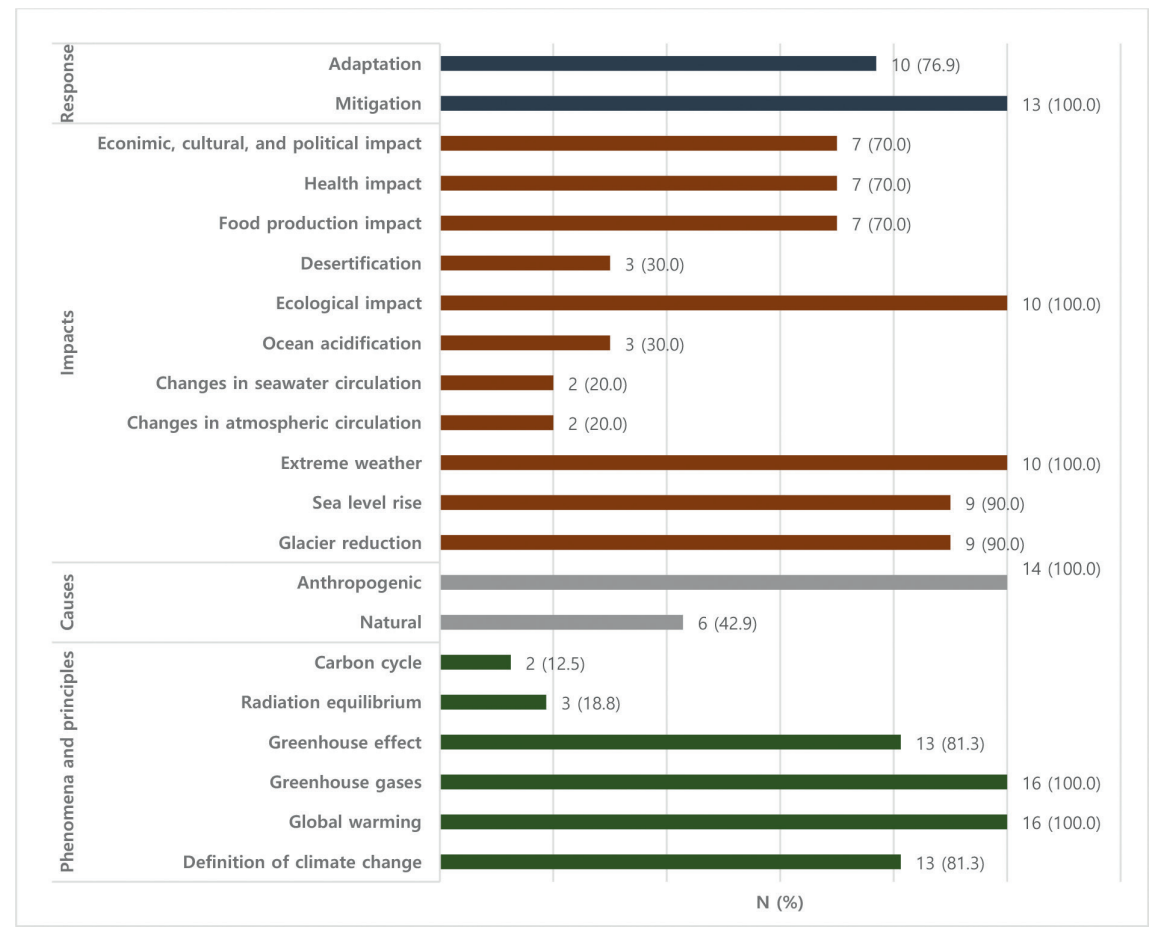

FIGURE 3 Analysis of the range of content

specification in structure. However, we also confirmed that elementary school programs often had a degree of specification that was low (63.6\%), while in middle or high school, more than $80 \%$ of the programs were developed with high degree of specification.

The range of content in the structure of the programs is shown in Figure 3. This represents the number and proportion of programs that contained each 


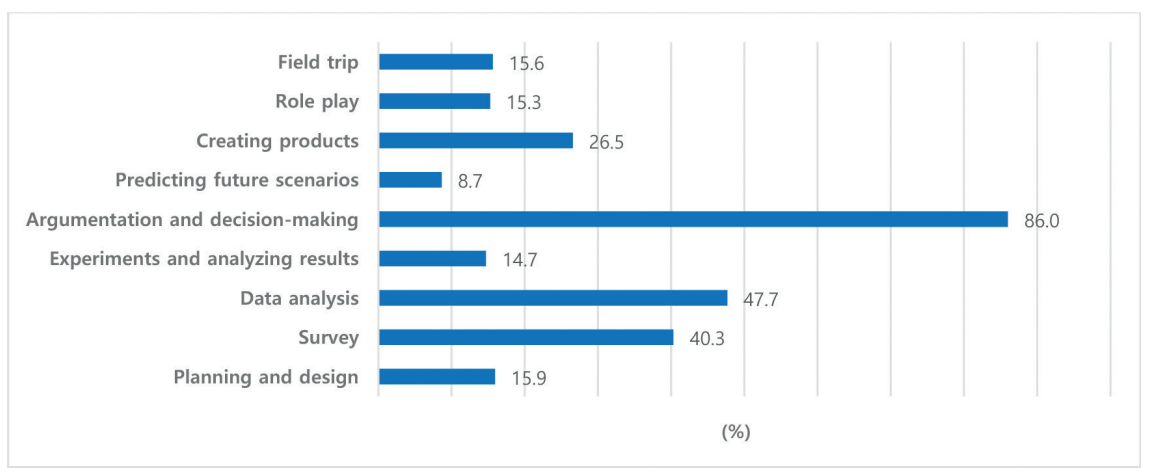

FIGURE 4 Analysis of the activity elements

content element. Through this, we identified not only the basic concepts that were most essential in CCE programs, but also extended concepts that were further addressed in some programs. For example, global warming, greenhouse gases, anthropogenic causes of climate change, extreme weather, ecological impact, and mitigation were very basic concepts covered in all programs. Radiative equilibrium, carbon cycle, natural causes of climate change, changes in atmospheric and sea water circulation, ocean acidification, and desertification have been used as more extensive concepts.

Finally, the results of analyzing the activity elements included in the programs are shown in Figure 4. Argumentation and decision-making (86.0\%) accounted for the largest proportion, followed by data analysis (47.7\%) and survey (40.3\%). Predicting future scenarios $(8.7 \%)$ was included in the least proportion.

\subsection{Content Analysis}

The average ratio of the areas of CCE, such as, knowledge, skills, values and attitudes, and participation and action, across the entire program are presented in Figure 5 , and the results of analyzing the sub-areas of those areas are shown in Figure 6. Overall, knowledge (34.4\%) and skills (31.7\%) occupied high proportions, while values and attitudes (16.6\%) and participation and action (17.4\%) were reflected relatively less.

In the knowledge area, the rate of responsive knowledge (7.9\%) was smaller than scientific knowledge (12.8\%) and relational knowledge (13.7\%). In the skills area, scientific thinking $(18.8 \%)$ was reflected much more than socioscientific reasoning $(5.2 \%)$ or reflexivity $(7.7 \%)$. Values and attitudes were generally reflected at low rates. The highest rates in this area were emotional and ethical empathy (5.4\%), global citizenship (4.3\%), ecological perspective 
Knowledge $\square$ Skills $\square$ Values \& Attitudes Participation \& Action

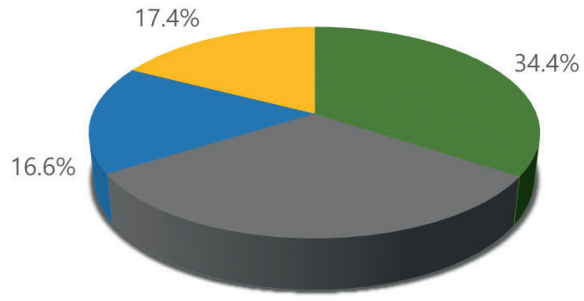

$31.7 \%$

FIGURE 5 Analysis of each area of content

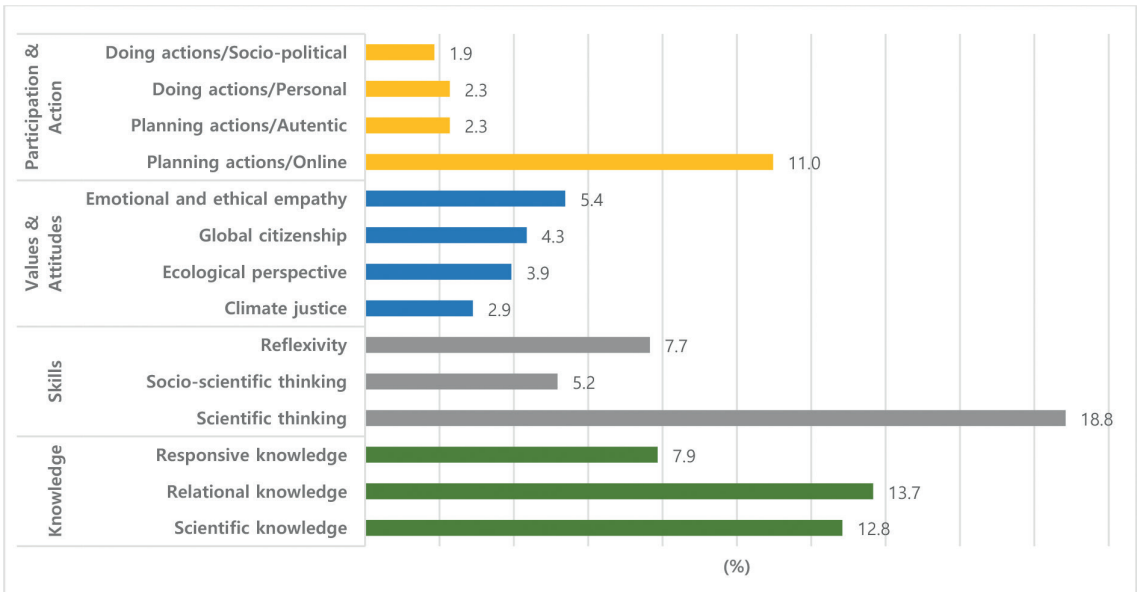

FIGURE 6 Analysis of sub-areas of content

$(3.9 \%)$, and climate justice $(2.9 \%)$. Participation and action were also reflected at low rates, most of which involved planning actions (13.3\%) and a few expanded to doing actions (4.1\%). In addition, most of the action planning was related to the online context (11.0\%), with very little related to the authentic context $(2.3 \%)$. As for doing actions, actions at the personal level $(2.3 \%)$ were included a little more than socio-political actions (1.9\%).

We also compared the reflection of content areas in programs by school level. The results are shown in Figure 7. At all school-level programs, knowledge and skills were reflected most. We also confirmed that participation and action were emphasized in elementary school programs more than in middle or high school CCE programs. 


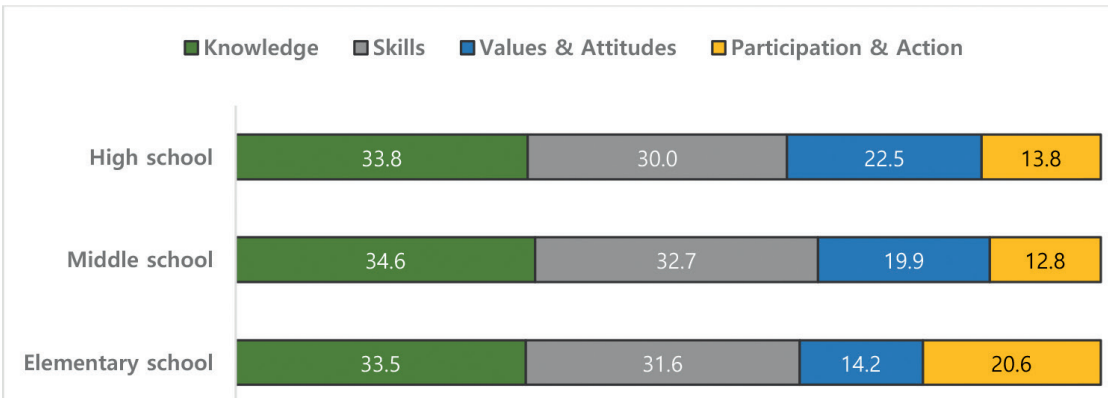

(\%)

FIGURE 7 Comparison of content areas in programs by school level

\subsection{Characteristics of the AEccE Programs}

Based on the results of the content analysis of the programs, we classified the programs with relatively strong emphasis on participation and action as AECCE programs and those that did not as typical CCE programs. Figure 8 compares the reflection of content areas in an example of a typical CCE program and an AECCE program. Seven of the 16 programs were classified as AECCE programs.

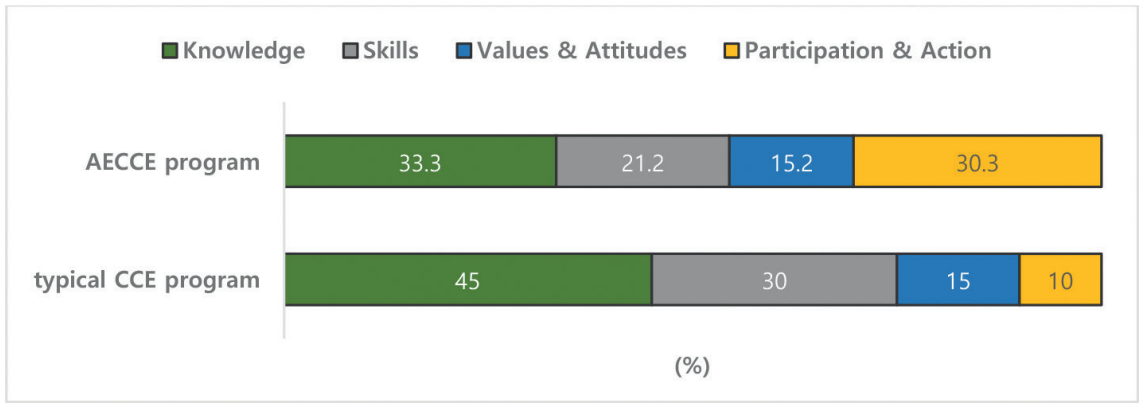

FIGURE 8 Example of a typical CCE program and an AECCE program

Note. Each example was from A (typical CCE) and D (AECCE) program

The results of analyzing the structural features of AECCE programs were as follows. We found the AECCE programs were particularly focused on the elementary level, and high school level programs were not included in the AECCE programs. On average, AECCE programs included more learning topics than typical CCE programs. The average number of learning topics was $7 \cdot 3$ in typical CCE programs and 9.3 in AECCE programs. We also found that AECCE programs were developed with a low degree of specification in structure, especially when dealing with the impacts of climate change. They required students 
TABLE 6 Topics presented on the impact of climate change, depending on the degree of specification

High degree of specification (L2)

Low degree of specification (D)

- Impact on sea level rise

- Impact on community

- Impact on snow and glacier cover

- Impact on country

- Impact on severe weather

- Global impact

- Impact on natural ecosystems

- Predicted impact on agricultural productivity

- Impact on food production

- Impact on fire on wildland

- Impact mortality

- Impact on asthma

Note. The examples were from L2 (high degree of specification) and D (low degree of specification) program, as shown in Table 4.

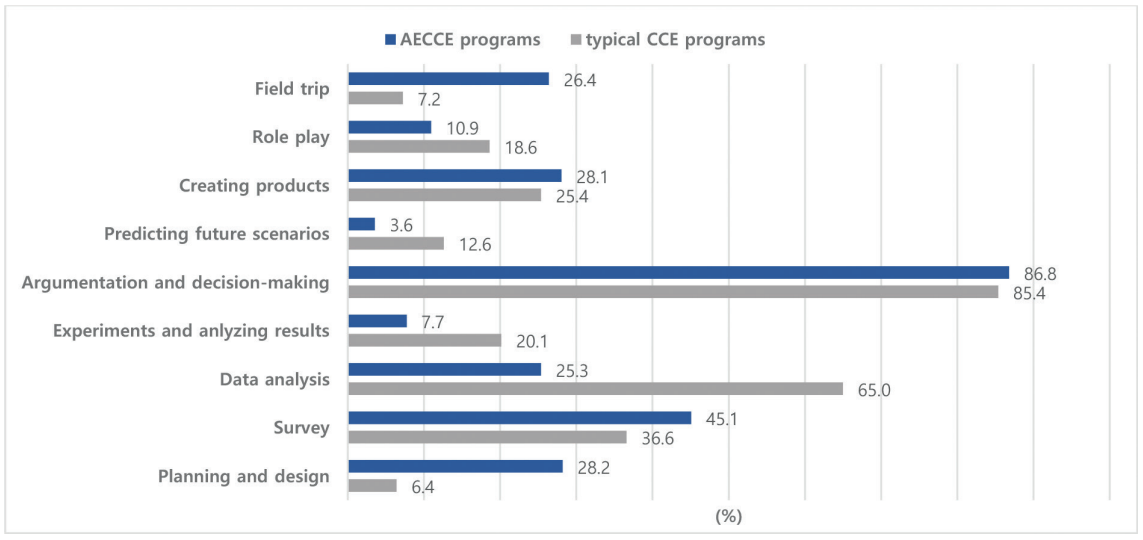

FIGURE 9 Comparison of proportions of activity elements between the typical CCE and AECCE programs

to explore the various impacts of climate change on their own. Table 6 shows examples of topics presented on the impact of climate change in two programs with high or low degrees of specification.

Activity elements, especially planning and design and field trips, were included in AECCE programs much more than in typical CCE programs. The results of analyzing the reflection of activity elements in typical CCE programs and AECCE programs are shown in Figure 9. 


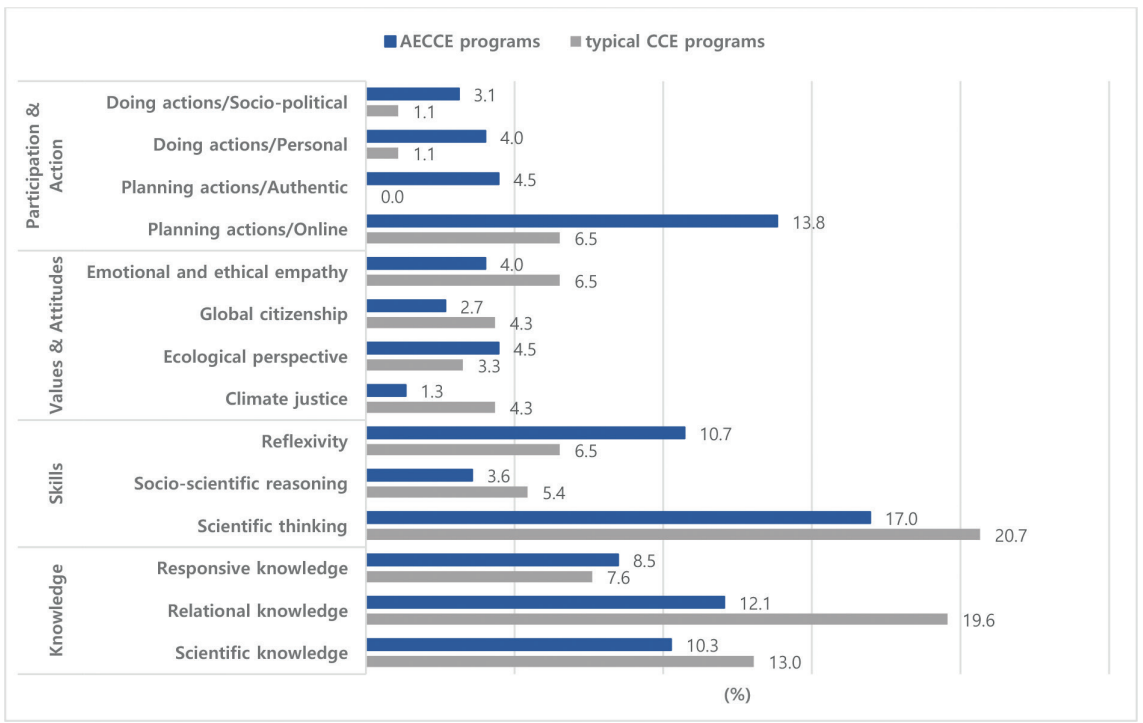

FIGURE 10 Comparison of the proportions of the sub-areas between the typical CCE and AECCE programs

Figure 10 compares the results of detailed analysis of the content of typical CCE programs and AECCE programs. In the AECCE programs, the three types of knowledge were relatively balanced, while the typical CCE programs lacked responsive knowledge. Within the skills area, it was remarkable that typical CCE programs were more focused on scientific thinking, whereas AECCE programs reflected more reflexivity with scientific thinking. Examples of activities with reflexivity in the programs investigated were as follows. The characters in parenthesis represent the programs (see Table 4).

- Tracking carbon emissions in one's home, school, and community (B, D, E, F, I, J, K1, K2, M, N)

- Finding carbon dioxide hidden in objects (A, F, G)

- Predicting the country's environmental crisis clock based on the status of climate change (B)

- Checking the climate change crisis index related to lifestyles (B)

Values and attitudes were relatively poorly reflected in both typical CCE programs and AECCE programs. The most significant differences between the typical CCE and AECCE programs were related to the area of participation and action. In AECCE programs, action plans were more often linked to actual actions than they were in typical CCE programs. In addition, AECCE programs included planning actions in authentic contexts along with online contexts, whereas in typical CCE programs it was difficult to find examples of planning 
actions in authentic contexts. Examples of activities that led students to plan response actions in authentic contexts were:

- Researching and writing reports about where families or schools are wasting energy (B, D, F, I, J, N)

- Finding where carbon is emitted and creating environmental map for the village $(\mathrm{F})$

- Taking photos confirming the impact of climate change in the local community (M)

- Interviewing older people about environmental changes in their local communities (M)

\subsection{Comparison of Characteristics of Korean and International AECCE Programs}

The seven programs classified as AECCE consisted of five Korean programs and two international programs, so we compared the characteristics between them. Figure 11 shows the comparison of the proportions of activity elements between Korean and international AECCE programs. Surveys and data analysis were remarkable in Korean AECCE programs, while experiments and analyzing results were much more reflected in international AECCE programs.

The results of analyzing the areas of content in Korean and international AECCE programs are shown in Figure 12. The main differences in content areas were that Korean AECCE programs included knowledge at the highest rate (32.7\%), while international AECCE programs reflected skills (40.7\%) the most.

Figure 13 compares the reflections of each sub-area of knowledge, skills, values and attitudes, and participation and action in Korean and international AECCE programs. The most prominent differences were identified in

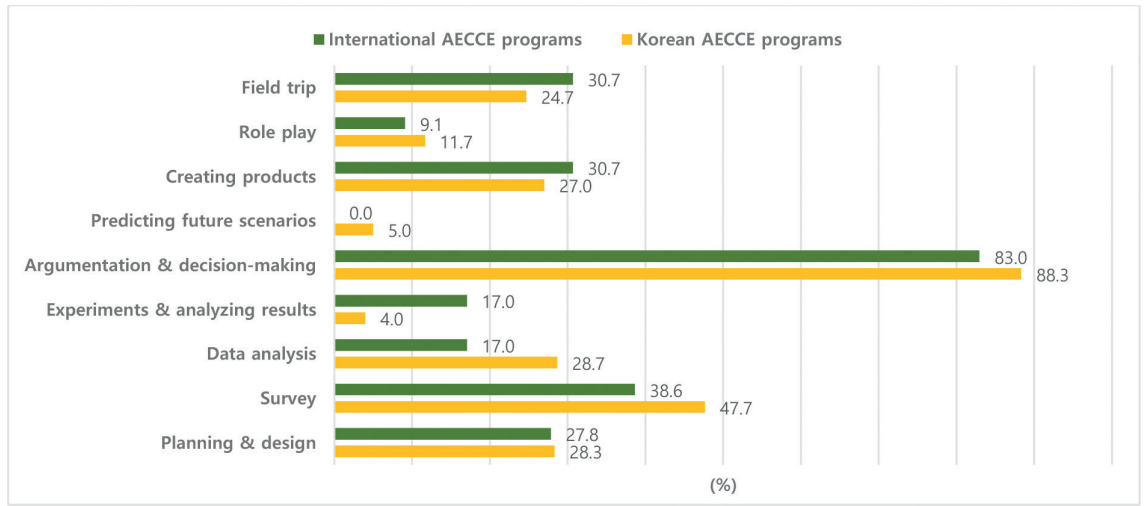

FIGURE 11 Comparison of the proportions of activity elements in Korean and international AECCE programs 


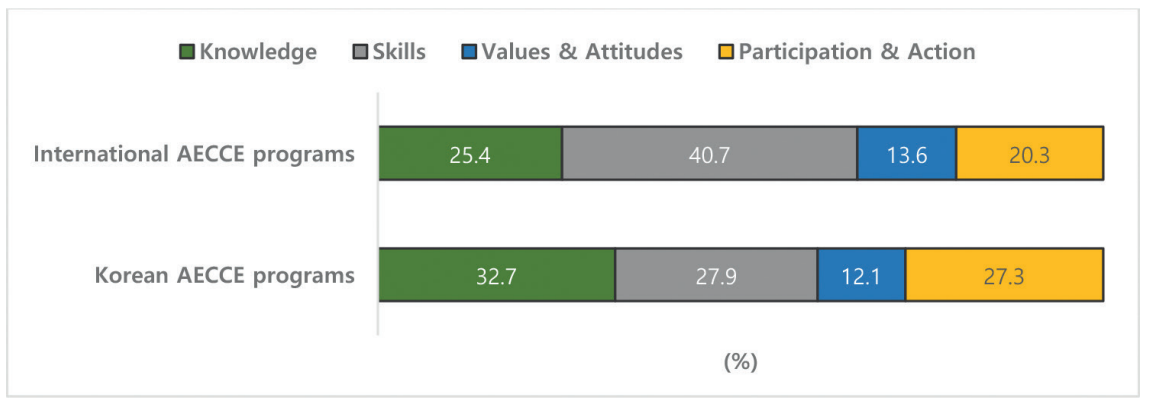

FIGURE 12 Comparison of the proportions of the areas of content in Korean and international AECCE programs

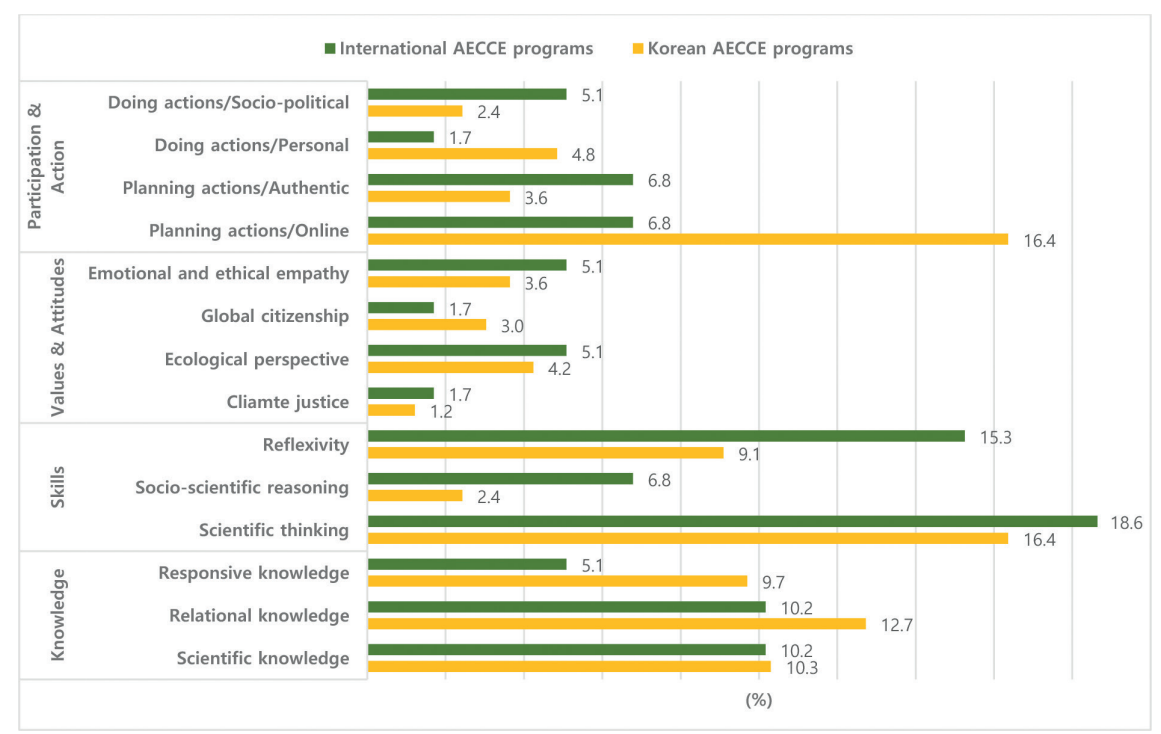

FIGURE 13 Comparison of the proportions of sub-areas in Korean and international AECCE programs

the areas of skills and participation and action. In the area of skills, the focus on scientific thinking was more pronounced in Korean AECCE programs. In international AECCE programs, reflexivity was almost as stressed as scientific thinking. In the area of participation and action, noticeable differences were identified for both the context of planning actions and the level of actions. In the international AECCE programs, the contexts for planning actions were balanced against both the online and authentic contexts, while in the Korean AECCE programs, it was heavily concentrated in the online contexts. In addition, international AECCE programs included more socio-political actions than personal-level actions. Conversely, in Korean AECCE programs, actions 
were more often conducted at the personal level than at the socio-political level. Examples of socio-political actions were:

- Creating posters, UCC, etc. on climate change issues and organizing exhibitions or campaigns (B, C, D, F, J, K1, K2, M, N)

- Creating a blog or writing an article for the local newspaper to share and discuss climate change issues $(\mathrm{K}, \mathrm{K} 2, \mathrm{M}, \mathrm{N})$

- Organizing social groups and planting trees in local areas $\left(\mathrm{K} 1, \mathrm{~K}_{2}, \mathrm{M}\right)$

- Organizing a bazaar and donating for those vulnerable to climate change $(\mathrm{J}, \mathrm{K} 1, \mathrm{~K} 2, \mathrm{~N})$

\section{$6 \quad$ Conclusion and Discussion}

The purpose of this study was to analyze existing CCE programs in various ways, with a focus on fostering citizen activists to respond to climate change. We developed frameworks for analyzing CCE programs, analyzed the structure and content of CCE programs and the characteristics of AECCE programs, and compared the characteristics of Korean and international AECCE programs. The conclusions of the study are as follows.

The structure and content of CCE programs were mostly developed for elementary school students and emphasized argumentation and decisionmaking for activity elements. The characteristics of their content areas included a higher proportion of knowledge and skills than values and attitudes and participation and action. More specifically, scientific and relational knowledge, scientific thinking, and planning actions in online contexts were emphasized. CCE programs with relatively strong emphasis on participation and action were classified as AECCE programs.

AECCE programs were mostly targeted at the elementary school level, and they had the following distinctive characteristics compared to typical CCE programs: On average, AECCE programs included more learning topics than typical CCE programs, and AECCE programs were developed with a low degree of specification in their structures. AECCE programs also put more emphasis on reflexivity with scientific thinking and planning actions in authentic contexts than typical CCE programs did. AECCE programs in Korea had more emphasis on scientific knowledge and thinking and personal level actions in online contexts, while international AECCE programs showed a balance between scientific thinking and action-related skills, such as reflexivity and planning more socio-political actions in online and authentic contexts.

It is quite encouraging to know that many quality CCE programs have been developed worldwide considering the urgency of climate crisis. Some 
CCE programs are well balanced in terms of the four major areas of content analysis: knowledge, skills, values and attitudes, and participation and action. Others still lack balance, especially in the area of participation and action, which seems crucial in transforming our society. Many Korean AECCE programs need to be improved to achieve such a balance.

From the findings, even though research and practice in ssi education have been spreading, they are still in the developing stage in many regions of the world, including Korea. There seem to be conflicts between the ssi education approach and educational systems and cultures. Rigid boundaries among school subjects, subject matter-based teacher certifications, and test-oriented school learning are examples of sources of conflict that inhibits action-oriented CCE.

From the results of the study, when developing educational programs to improve $\mathrm{CCE}$, the following aspects need to be considered. First, the development of AECCE programs is proactively required not only in elementary schools but also in middle and high schools. Because climate change is a long-term challenge that requires constant attention and response, CCE programs also need to be implemented across a variety of ages from the perspective of lifelong learning rather than focusing on specific ages. Kim et al. (2013) also stressed that appropriate education programs, from pre-school education to out-ofschool education, should continue to be implemented to cultivate the competency to drive change by participating in problem solving on global issues.

Additionally, the areas of values and attitudes and participation and action should be considered more clearly, in addition to knowledge and skills. The values and attitudes that individuals perceive and pursue in relation to climate change issues are important in responding to climate change (Choi et al., 2011). Participation and action experiences also play an important role in improving action competency (Jensen \& Schnack, 1997) for voluntary and sustainable actions.

The low degree of specification in structure and the emphasis on reflexivity can be usefully considered when designing AECCE programs. These were characteristics of the AECCE programs identified in this study compared to the typical CCE programs. For example, when dealing with the impacts of climate change, presenting a few macro themes and having students investigate the relevant details could be systematically linked to planning their actions. Reflexivity also plays an important role in proactively responding to common risks by making the problem meaningfully related to one's own life (Beck, 1986).

For Korean AECCE programs, it is especially necessary to balance authentic contexts with online contexts for planning actions and further expand personal actions into socio-political actions. Planning actions in authentic contexts has the advantage of being able to lead to context-specific responses that reflect 
the contextual characteristics of communities. Trott (2017) confirmed that after applying a community-based participatory CCE program, participants experienced an enhanced sense of agency and practiced specific actions in the contexts of their families and communities. Socio-political action has a more active meaning than personal-level action, and its importance is increasing in relation to activism (Bencze et al., 2012).

\section{Limitations of this study}

A limitation of this study is that it cannot be generalized to all existing CCE programs. In addition, since the analysis of the characteristics of the programs in this study was dependent on data from the literature of these programs, it could be different from the results of analyzing the actual implementation of the programs. Therefore, in the follow-up studies, analysis of the actual implementation of the programs needs to be added. This study is meaningful in that it contributed to enriching the current understanding of how to foster the education of citizen activists through CCE. We hope that this study will be useful in the analysis of CCE programs and the development of future CCE programs.

\section{Abbreviations}

AECCE Action-emphasized Climate Change Education

CCE Climate Change Education

IPCC Intergovernmental Panel on Climate Change

UNFCC United Nations Framework Convention on Climate Change

\section{Acknowledgements}

This work was supported by the Ministry of Education of the Republic of Korea and the National Research Foundation of Korea (N RF-2019S1A5A2Ao3048062).

\section{Ethical Considerations}

The data collected from this article did not involve human subjects so no human subjects approval was necessary. 


\section{About the Authors}

Na-Eun Park received a master's degree from the Department of Science Education at Seoul National University in Seoul, Republic of Korea. She is interested in improving science education programs for learning about socioscientific issues. In particular, her research focuses on improving climate change education programs to foster citizens who can take action to respond to climate change. Her research aims to analyze climate change education programs to find and implement improvements.

Seung-Urn Choe is emeritus professor in the Department of Earth Science Education at Seoul National University in Seoul, Republic of Korea. He holds a bachelor's and master's degree from the Department of Astronomy, Seoul National University. He also holds a Ph.D. in Astrophysics from the University of Minnesota in the United States. With a focus on scientific modeling, he developed and applied a variety of educational programs that enable students to socially construct scientific models. His research covers a variety of topics, including analysis of students' scientific argumentations and interactions on socio-scientific issues such as climate change, understanding of cognitive processes of scientifically gifted students, and improving students' scientific creativity.

Chan-Jong Kim is Professor in the Department of Earth Science Education at Seoul National University in Seoul, Republic of Korea. He received his bachelor's degree in Earth Science Education and master's degree in Geological Sciences from Seoul National University in the Republic of Korea. He also holds a doctoral degree in Science Education from the University of Texas at Austin in the United States. His research focuses on scientific modeling as an approach to scientific exploration and learning in a variety of subjects, contents, and contexts and on development and application of various methods for the analysis of collective talk with learning of science. He is particularly interested in education for diverse learners in Korean K-12 on global environmental risks such as climate change.

\section{References}

Aikenhead, G. (2007). Expanding the research agenda for scientific literacy. In C. Linder et al. (Eds.), Promoting scientific literacy: Science education research in transaction (pp. 64-71). Geotryckeriet. 
Anderson, A. (2012). Climate change education for mitigation and adaptation. Journal of Education for Sustainable Development, 6(2), 191-206.

Beck, U. (1986). Risk society: Towards a new modernity (translated by S. T. Hong, 1997). Saemulgyul.

Bencze, L., Sperling, E., \& Carter, L. (2012). Students' research-informed socio-scientific activism: Re/visions for a sustainable future. Research in Science Education, 42(1), 129-148.

Carlsson, M., \& Simovska, V. (2012). Exploring learning outcomes of school-based health promotion - a multiple case study. Health Education Research, 27(3), 437-447.

Choi, K. H., Kim, S. W., Lee, H. J., \& Krajcik, J., et al. (2013). 글로벌 리더가 알아야 할 과 학이야기. [Science Story for Global Leaders to Know 1]. Jeil.

Cordero, E. C., Todd, A. M., \& Abellera, D. (2008). Climate change education and the ecological footprint. Bulletin of the American Meteorological Society, 89(6), 865-872.

Dobson, A. (2003). Citizenship and the environment. Oxford University Press.

Hodson, D. (2010). Science education as a call to action. Canadian Journal of Science, Mathematics and Technology Education, 10(3), 197-206.

Hung, C. C. (2014). Climate change education: Knowing, doing and being. Routledge.

Hungerford, H. R., \& Volk, T. L. (199o). Changing learner behavior through environmental education. The Journal of Environmental Education, 21(3), 8-21.

Jensen, B. B., \& Schnack, K. (1997). The action competence approach in environmental education. Environmental education research, 3(2), 163-178.

Jeong, C. H. (2014). About the role and responsibility of education in the risk society. Theory and Practice of Education, 19(2), 1-22.

Jeong, C. K. (2010). ESD관점에 입각한 웹기반 기후변화교육이 초등학생의 환경의 식 및 태도에 미치는 영향. [Effects of the web-based climate change educational program on environmental awareness and attitudes of elementary school students from the viewpoint of ESD-focused on 5th grade]. [Unpublished master's thesis]. Seoul National University of Education, Seoul, Republic of Korea.

$\mathrm{Ju}, \mathrm{E} . \mathrm{K}$. (2017). 초등학생 대상 실천중심 기후변화교육 프로그램 개발. [Development of a practice-based education program on climate change for elementary school students]. [Unpublished master's thesis]. Gwangju National University of Education, Gwangju, Republic of Korea.

Kim, B. Y. (2011). The Implication of geographical and environmental education on debate about ecological citizenship. Korean Association of Geographic and Environmental Education, 19(2), 221-234.

Kim, C. H. (2019). 초등학교 고학년 대상 기후변화교육 프로그램의 개발 및 효과. [Development and effects of climate change education program for upper grade elementary students]. [Unpublished master's thesis]. Gwangju National University of Education, Gwangju, Republic of Korea. 
Kim, C. K., \& Choi, D. H. (2010). Thoughts on climate change education in Korea. The Korean Society for Environmental Education, 23(1), 1-12.

Kim, E. J., Yoo, Y. E., Shin, E. S., \& Park, E. H. (2013). An inquiry into and implication of school education and early childhood education for sustainable developments in Germany, England and Australia. Journal of Korea Open Association for Early Childhood Education, 18(4), 75-100.

Kim, G. R. (2015). 스토리텔링을 활용한 기후변화교육 프로그램 개발 및 적용. [Development and application of climate change education program using storytelling]. [Unpublished master's thesis]. Gwangju National University of Education, Gwangju, Republic of Korea.

Kim, H. O. (2013). 기후변화 교육프로그램이 초등학생의 환경 태도에 미치는 효과. [The effects of climate change education program on the environmental attitude of elementary school students]. [Unpublished master's thesis]. Kyungin University of Education, Incheon, Republic of Korea.

Kim, T. H. (2017). 초등학교의 기후소양교육을 위한 프로그램 개발 및 적용. [Development and application of program for elementary climate-literacy education]. [Unpublished master's thesis]. Gwangju National University of Education, Gwangju, Republic of Korea.

Kim, Y. R., \& Shin, D. H. (2013). Analysis of climate change education program between South Korea and North America. The Korea Society Energy and Climate Change Education, 3(1), 75-81.

Lester, B. T., Ma, L., Lee, O., \& Lambert, J. (2006). Social activism in elementary science education: A science, technology, and society approach to teach global warming. International Journal of Science Education, 28(4), 315-339.

Liu, X. (2013). Expanding notions of scientific literacy: A reconceptualization of aims of science education in the knowledge society. In N. Mansour \& R. Wegerif (Eds.), Science education for diversity (pp. 23-39). Springer.

Ministry of Foreign Affairs. (2015). Knowing climate change-frequently asked questions. Korea Ministry of Foreign Affairs.

Mogensen, F., \& Schnack, K. (2010). The action competence approach and the "new" discourses of education for sustainable development, competence and quality criteria. Environmental Education Research, 16(1), 59-74.

Oh, S. R. (2010). 탄소발자국 프로그램을 활용한 기후변화교육이 초등학생의 환경태 도에 미치는 영향. [The effects of a climate change education program on carbonfootprints on Grade 4 elementary schoolstudents' environmental attitudes]. [Unpublished master's thesis]. Seoul National University of Education, Seoul, Republic of Korea.

Oxfam Education. (2015a). Climate Challenge for 7-11 years. https://www.oxfam.org.uk/ education/resources/climate-challenge-7-11.

Oxfam Education. (2015b). Climate Challenge for 11-14 years. https://www.oxfam.org .uk/education/resources/climate-challenge-11-14. 
Pachauri, R. K., and Meyer, L. A. (Eds.). (2014). Climate Change 2014: Synthesis Report. Contribution of Working Groups I, II, and III to the Fifth Assessment Report of the Intergovernmental Panel on Climate Change. IPCC.

Park, H.C. (2012). 지구온난화 교육 프로그램을 통한 초등학생의 환경소양 변화에관 한 연구. [Study on changes in environmental literacy in elementary students through a global warming education program]. [Unpublished master's thesis]. Jeju National University, Jeju, Republic of Korea.

Park, S. Y., Lee, J. Y., \& Nam, Y. S. (2013). A Study on analysis of research about climate change education in elementary school. The Korean Society for Environmental Education, 26(3), 285-297.

Roberts, D. A. (2007). Scientific literacy/science literacy. In S.K. Abell \& N.G. Lederman (Eds.), Handbook of research on science education (pp. 729-280). Lawrence Erlbaum Associates.

Sadler, T. D., Klosterman, M. L., \& Topcu, M. S. (2011). Learning science content and socio-scientific reasoning through classroom explorations of global climate change. In T. D. Sadler (Ed.), Socio-scientific Issues in science classrooms: Teaching, learning and research (pp. 45-77). Springer.

Seo, W. S., Na, S. I., Jyong, C. Y., \& Kim, S. W. (1999). A content analysis of environmental education programs designed for elementary school students. The Korean Society for Agricultural Education and Human Resource Development, 31(3), 43-61.

Sharma, A. (2012). Global climate change: What has science education got to do with it? Science \& Education, 21(1), 33-53.

Stanford School of Earth, Energy and Environmental Sciences. (2011a). The science and policy of global climate change curriculum for high school. https://earth.stanford .edu/climate-change-ed/curriculum/high.

Stanford School of Earth, Energy and Environmental Sciences. (2011b). The science and policy of global climate change curriculum for middle school. https://earth.stanford. edu/climate-change-ed/curriculum/middle.

Trott, C. D. (2017). Engaging key stakeholders in climate change: A community-based project for youth-led participatory climate action. [Unpublished Doctoral dissertation]. Colorado State University, Boulder, CO, USA.

University of Jyväskylä, University of Helsinki. (2015). Climate change-effects and adaptation. IRRESISTIBLE. http://www.irresistible-project.eu/index.php/en/ resources/teaching-modules.

Woo, J. A. (2011). Development and application of a climate change education program in middle school science [Unpublished doctoral dissertation]. Korea National University of Education, Cheongju, Republic of Korea.

Yun, S. J. (2009). The current state and tasks of school climate change education. The Korean Society for Environmental Education, 22(2), 1-22. 